This item is the archived peer-reviewed author-version of:

All actions are emotional actions

\title{
Reference:
}

Nanay Bence.- All actions are emotional actions

Emotion Review - ISSN 1754-0739 - (2017) 
Running Head: Every action is an emotional action

Commentary

Every action is an emotional action

\section{Bence Nanay}

University of Antwerp - Philosophy

Correspondence to:

Bence Nanay

University of Antwerp - Philosophy

D 413, Grote kauwenberg 18 Antwerp 2000

Belguim 
Running Head: Every action is an emotional action

\begin{abstract}
In action theory, emotional actions are standardly treated as exceptions - cases where the 'normal' springs of action are not functioning properly. My aim here is to argue that this is not so. We have plenty of evidence - beautifully brought together in the present special issue - that emotions play a crucial and often constitutive role in all the important phases of action preparation and initiation. Most of our actions are less stupid than, say, Zidane's head-butt (a paradigmatic emotional action), but all of our actions have emotional components. Actions can be more or less emotional, but they are never completely non-emotional.
\end{abstract}

KEYWORDS: emotional action, action initiation, spinal excitability 
Here is a paradigm emotional action: in the dying minutes of the 2006 Soccer World Cup Final, the captain of the French team, Zinedine Zidane, widely recognized as the best player of all time, head-butted an Italian defender, Marco Materazzi. As a result, he was sent off and France lost the final. A pretty stupid thing to do.

This counts as an emotional action because his emotion (his anger, presumably, or maybe his pride (we still don't know exactly how Materazzi provoked him) is what played a crucial role in causing and motivating this action. If he had deliberated about his action calmly and rationally, in terms of maximizing the probability of the satisfaction of his long-standing desires given his background beliefs (about, for example, how headbutting inevitably leads to a red card), he would have chosen not to head-butt Materazzi. He was acting foolishly, impulsively and irrationally, following his feelings, not his reason. At least that is the standard story about emotional actions.

My aim here is to argue that emotional actions are not exceptions - they are the norm. Most of our actions are less stupid than Zidane's, but all of our actions have emotional components. Actions can be more or less emotional, but they are never completely non-emotional. ${ }^{1}$

One of the most important developments in the last decade or so in action research concern the variety of causal and constitutive links between emotion and action and this new paradigm is what this special issue is about. We have strong and multifaceted evidence that emotions play a crucial and often constitutive role in all stages of action preparation and execution and different papers in the special issue summarize the evidence for these diverse lines of influence very thoroughly. As Peter Railton shows, acting for a reason is deeply intertwined with, and helped by, emotions (Railton 2017). On the action execution side, Blakemore and Vuilleumier 2017 contribution gives rich

\footnotetext{
${ }^{1}$ This claim is the converse of the emerging consensus in emotion theory, namely, that all emotions are action-al (by, e.g., having action-tendencies as constitutive components), which is very well-represented in this special issue (see especially Moors et al. 2017).
} 
evidence that those representations (motor representations (Jeannerod 1997) or pragmatic representations (Nanay 2013, Nanay 2014)) that specify the exact bodily movements of action execution are also influenced by our emotions.

Beliefs, desires, intentions and motor representations/pragmatic representations do not themselves move us to act. Myles Brand made a distinction between those antecedents of action that specify how we should move and those that in fact move us to act (Brand 1984). This distinction looms large in the cognitive neuroscience of action (see, e.g., Haggard 2005, Lau et al. 2004) and especially in the work of Marc Jeannerod who repeatedly emphasized that even if we have our desires, beliefs, intentions and motor representations/pragmatic representations in place, this does not imply that we perform the action (Jeannerod 1997, 2006). Something extra is needed and I want to focus on this 'something extra' here: the mental antecedent of action that moves us to act. Here is an evocative literary description of the necessity of this 'moving to act' component by Robert Musil:

I'm lying on one side in bed: [and I think] now you ought to turn yourself over. This thought goes marching on in a state of complete equality with a whole set of other ones: for example, your foot is starting to feel stiff, the pillow is getting hot, etc. It is still a proper act of reflection; but it is still far from breaking out into a deed. On the contrary, I confirm with a certain consternation that, despite these thoughts, I still haven't turned over. As I admonish myself that I ought to do so and see that this does not happen, something akin to depression takes possession of me, albeit a depression that is at once scornful and resigned. And then, all of a sudden, and always in an unguarded moment, I turn over. ${ }^{2}$

\footnotetext{
${ }^{2}$ Robert Musil: Diaries. New York: Basic Books, 1999, p. 101.
} 
All the relevant beliefs, desires, intentions and motor/pragmatic representations are in place at time T1, but I just fail to move. At a later time T2 I do move. My beliefs, desires, intentions or motor/pragmatic representations between T1 and T2 do not change. What does change is the mental state that moves us to act. And I hope to show that this 'moving to act' state is also intricately intertwined with our emotions - something that none of the papers in this special issue deals with explicitly (although some of the relevant empirical findings are mentioned tangentially in Blakemore and Vuilleumier 2017).

Neuroscientists of action make a distinction between the preparation for a movement and the execution of that movement. One major difference between these two phases of action execution is the inhibition of action during preparation and the lifting of this inhibition shortly before the execution begins (see Porter and Lemon 1993 for a summary). And the main difference between these two phases of action execution is at the segmental spinal level. More precisely, there is a sharp decrease of spinal reflexes (more precisely, T-reflexes) during preparation for a movement (which prevents motor neurons from spontaneous firing) and increase again shortly before execution. (Bonnet and Requin 1982, Fourkas et al. 2006).

In short, increased spinal excitability is necessary for the initiation of action - if the spinal excitability is decreased, there is no bodily movement. But increased spinal excitability is not sufficient for the initiation of action as spinal excitability is also increased in the case of motor imagery (when no action is executed - see Bonnet et al. 1997, Li et al. 2004, Aoyama and Kaneko 2011). The increase in spinal excitability is not what moves us to act. But it is a precondition for the tokening of the state that moves us to act.

And the crucial piece of evidence, from the point of view of this paper, is that spinal excitability is reliably increased by affective stimuli (Baumgartner et al. 2007, 
Nogueira-Campos et al. 2014, see also the references in Blakemore and Vuilleumier's contribution). To simplify a little, whether and when the action is executed is partially dictated by our emotions. Not just Zidane's action, but also our prosaic actions such as turning around in one's bed.

Consider akratic actions: say, you need to write a grant proposal, but the vague idea of watching TV begins to creep into my mind. But I resist the temptation. Then suddenly I find myself reaching for the remote control. What changed? Again, not my beliefs, my desires, my intentions or my motor/pragmatic representations. What changed is the 'moving to act' component and my suggestion is that it is due to emotional interference, just as Musil suggested: "something akin to depression takes possession of me, albeit a depression that is at once scornful and resigned". This interfering emotion may not be conscious (all five contributions in this special issue talk about the possibility of unconscious emotions and their potential role in action), but it is an emotion all the same.

Treating akratic actions as emotional actions is hardly a novelty (see Tappolet 2003). But the similarity between akratic actions and emotional actions goes far beyond the superficial similarity that neither seems to be what maximally rational agents should do. I attempted to identify the role emotions play in the initiation of akratic actions. And this role - in triggering the actual bodily movement - is not specific to akratic actions: it is a necessary feature of all of our actions (although the emotion in question may not always be transparent to us).

A final worry: one may wonder just how important this causal influence of emotions on action initiation is. (see also Scarantino 2017). Not all causal influences are essential for the causal explanation of a phenomenon: LSD in the blood stream causally influences our visual experiences, but this does not mean that any causal explanation of visual experiences need to talk about LSD or that all visual experiences are LSD-laden. 
So I want to show the explanatory importance of the link between emotion and actioninitiation. Here is the disanalogy with the LSD case: our visual experience depends reliably on many things - mostly on the scene in front of our eyes. And the dependence of our visual experience on LSD in the blood stream is not as reliable as its dependence on other things, for example, on the scene in front of our eyes. But spinal excitability (more precisely, the strength of T-reflexes) does not depend reliably on many things - in fact, emotions seem to be the most reliable link here (more reliable than motor imagery, for example, see esp. Rodrigues et al. 2010) -. Emotions can push us over the threshold of action execution more reliably than anything else. ${ }^{3}$ In short, we cannot understand action initiation without talking about emotions. Not just in the case of Zidane's headbutt, but also in the case of all our actions.

\section{References:}

Aoyama, T. and F. Kaneko 2011 The effect of motor imagery on gain modulation of the spinal reflex. Brain Research 1372: 41-48.

Baumgartner, T., Willi, M. \& Jäncke, L. 2007 Modulation of corticospinal activity by strong emotions evoked by pictures and classical music: a TMS study. Neuroreport 18, 261-265

Blakemore, R. H. and P. Vuilleumier 2017 An emotional call to action: Integrating affective neuroscience in models of motor control. Emotion Review

Bonnet M. and J. Requin 1982 Long loop and spinal reflexes in man during preparation for intended directional hand movements. Journal of Neuroscience 2: 90-96.

\footnotetext{
${ }^{3}$ Counting to three and doing it (which some would label as 'the will') also does the trick, of course, but then the question is what initiates the action of counting to three...
} 
Bonnet M., Decety J, Jeannerod M, Requin J (1997) Mental simulation of an action modulates the excitability of spinal reflex pathways in man. Cogn Brain Research 5: $221-228$.

Brand, Myles 1984 Intending and Action. Cambridge, MA: The MIT Press.

Fourkas, A. D., Ionta, S., \& Aglioti, S. M. (2006). Influence of imagined posture and imagery modality on corticospinal excitability. Behavioural brain research, 168(2), 190-196.

Haggard, P. 2005 Conscious intention and motor cognition. Trends in Cognitive Sciences 9: 290-295.

Jeannerod, M. (1997), The Cognitive Neuroscience of Action. Oxford: Blackwell.

Jeannerod, M. 2006 Motor Cognition. New York: Oxford University Press.

Lau, H. C., R. D. Rogers, P. Haggard and R. R. Passingham 2004 Attention to intention. Science 303: 1208-1210.

Li, Sheng, Derek G. Kamper, Jennifer A. Stevens and William Z. Rymer 2004 The effect of motor imagery on spinal segmental excitability. Journal of Neuroscience 24: 96749680.

Moors, A., Y. Boddez \& J. De Houwer 2017 The power of goal-directed processes in the causation of emotional and other actions. Emotion Review

Nanay, Bence 2013 Between Perception and Action. Oxford: Oxford University Press.

Nanay, Bence 2014 Naturalizing action theory. In: M. Sprevak and J. Kallestrup (eds.): New Waves in the Philosophy of Mind. Palgrave Macmillan, 2014, pp. 226-241.

Nogueira-Campos, A. A., L. A. S. de Oliveira, V. Della-Maggiore, P. O. Esteves, E. de Carvalho Rodrigues and C. D. Vargas 2014 Corticospinal excitability preceding the grasping of emotion-laden stimuli. PLoS One 9 (4): e94824.

Porter, R. and R. Lemon 1993 Corticospinal function and voluntary movement. Oxford: Clarendon Press. 
Railton, P. 2017 At the core of our capacity to act for a reason: The affective system and dynamic model-base learning and control. Emotion Review

Rodrigues E. C., Lemos T., Gouvea B., Volchan E., Imbiriba L. A., Vargas C. D. 2010 Kinesthetic motor imagery modulates body sway. Neuroscience 169: 743-750.

Scarantino, A. 2017 Do emotions cause actions, and if so, how? Emotion Review

Tappolet, Ch. 2003 Emotions and the intelligibility of akratic action. In: S. Stroud and Ch. Tappolet (eds.): Weakness of Will and Practical Irrationality. Oxford: Oxford University Press, pp. 97-120. 